\title{
Analgesic efficacy of laser acupuncture and electroacupuncture in cats undergoing ovariohysterectomy
}

\author{
Felipe F. NASCIMENTO ${ }^{1)}$, Vírginia I. MARQUES ${ }^{1)}$, Giulianne C. CROCIOLLI ${ }^{1}$, \\ Gabriel M. NICÁCIO ${ }^{1)}$, Isabela P. A. G. NICÁCIO') and Renata N. CASSU1)* \\ 1)Department of Veterinary Surgery and Anestesiology, Faculty of Veterinary Medicine, Universidade do Oeste \\ Paulista, Unoeste, 19067-175, Presidente Prudente, Brazil
}

J. Vet. Med. Sci.

81(5): 764-770, 2019

doi: $10.1292 / j v m s .18-0744$

Received: 17 December 2018 Accepted: 13 March 2019 Published online in J-STAGE: 25 March 2019

\begin{abstract}
The aim of this study was to compare the effects of laser acupuncture and electroacupuncture on postoperative pain and analgesic requirements in cats. In a prospective, randomized and blinded clinical study, thirty cats undergoing ovariohysterectomy were sedated with intramuscular (IM) ketamine $(5 \mathrm{mg} / \mathrm{kg})$, midazolam $(0.5 \mathrm{mg} / \mathrm{kg})$, and tramadol $(2 \mathrm{mg} / \mathrm{kg})$. Before the induction of anesthesia, the animals were randomly distributed into three groups of ten cats each: LA: bilateral Stomach 36 (ST-36) and Spleen 6 (SP-6) acupoints were stimulated with an infrared laser; EA: bilateral ST-36 and SP-6 acupoints were stimulated with an electrical stimulus; Control: no acupuncture was applied. Postoperative analgesia was evaluated in the first $24 \mathrm{hr}$ post-extubation using the Interactive Visual Analogue Scale and UNESP-Botucatu Multidimensional Composite Pain Scale. Rescue analgesia was provided with IM tramadol (2 mg/ $\mathrm{kg}$ ), and the pain scores were reassessed $30 \mathrm{~min}$ after the rescue intervention. If the analgesia remained insufficient, meloxicam ( $0.2 \mathrm{mg} / \mathrm{kg} \mathrm{IM}$, single dose) was administered. Data were analyzed using $t$-tests, the Mann-Whitney $U$ test, and Friedman test. $P<0.05$ was considered significant. The pain scores did not significantly differ between the treatment groups at any time point $(P>0.05)$. The prevalence of rescue analgesia was significantly higher in the Control group than in the LA and EA groups ( $P=0.033$ ). Preoperative laser and electroacupuncture reduced the need for rescue analgesia during the first $24 \mathrm{hr}$ after ovariohysterectomy.
\end{abstract}

KEY WORDS: analgesia, electroacupuncture, laser acupuncture, ovariohysterectomy

Although opioids are widely used in perioperative small animal practice settings, the use of large doses of these analgesics has been associated with several adverse events, such as vomiting, nausea, bradycardia, dysphoria, and panting [4]. In addition, opioids produce a short duration of action, and when administered alone do not always provide adequate postoperative analgesia [32]. Recent evidence has demonstrated that opioids play an important role in glia activation, which results in a cascade of events that contribute to the increased nociception [22]. Acute opioid tolerance and opioid-induced hyperalgesia have been reported in humans following intraoperative administration of high doses of opioids [15].

In order to minimize the adverse events of opioids and optimize postoperative pain management, the incorporation of nondrug therapies, as part of a multimodal analgesia protocol has been proposed $[25,32]$. Electrical stimulation of acupuncture needles, electroacupuncture (EA), is a pain-relieving method that has been suggested to induce modulatory effects that activate the descending pain inhibitory system, including the opioidergic, adrenergic, and serotonergic pathways in both the central and peripheral nervous systems [18]. In addition, evidence suggests that connective tissue-related mechanisms are also involved in the analgesic effect mediated by needle-based acupuncture [26]. Acupuncture needling causes sustained stretching of connective tissue, which may act as a mechanical stimulus, resulting in a release of adenosine triphosphate (ATP) in local subcutaneous tissues that act on A1 receptors in sensory fibers, exerting modulation on the pain-pathways [27].

The benefits of EA as an adjuvant for postoperative pain management have been reported in both human $[24,28,36]$ and veterinary medicine $[7,17]$. The majority of studies suggest that EA produces a $20-50 \%$ decrease in postoperative opioid requirements $[17,24,36]$.

Another therapeutic modality that has been evaluated as potentially useful as an analgesic adjuvant is stimulation of the acupoints with an infrared laser [21, 29]. Both electrical and laser applications to acupuncture points can induce similar effects in the brain and periphery [29]. Despite this, different mechanisms have been proposed for the actions of electrical and laser stimulus

*Correspondence to: Cassu, R. N.: renavarro@uol.com.br, navarro@unoeste.br

O2019 The Japanese Society of Veterinary Science

This is an open-access article distributed under the terms of the Creative Commons Attribution Non-Commercial No Derivatives (by-nc-nd) License. (CC-BY-NC-ND 4.0: https://creativecommons.org/licenses/by-nc-nd/4.o/) 


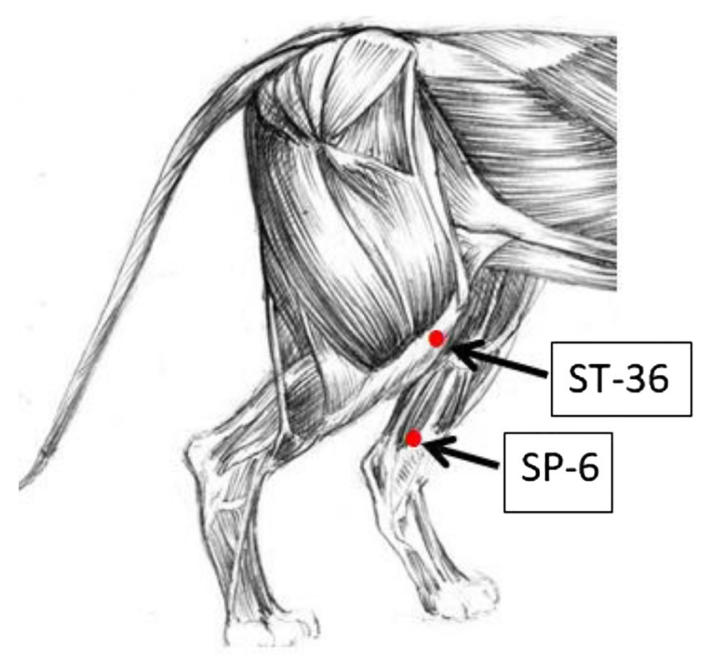

Fig. 1. Anatomical location of the acupoints ST-36 and SP-6.

$[1,41]$. Recent studies have found that low-level laser therapy can increase the mitochondrial activity, particularly of cytochrome $\mathrm{C}$ oxidase, leading to biostimulation of various responses, including the increase in ATP synthesis, cellular respiration, and metabolism, which promotes the enhancement of blood flow and, in turn, reduces pain $[1,14]$.

The main advantages of laser acupuncture (LA) over EA are shorter session lengths and the absence of discomfort and risk of infection, as it is a non-invasive technique [29]. Two recent reports demonstrated relevant analgesic effects using LA as an adjuvant for the treatment of postoperative pain in dogs and cats $[31,38]$. To the authors' knowledge, a comparison between EA and LA for postoperative pain management in cats has not been performed.

The objective of this study was to compare the safety and clinical effects of laser acupuncture and electroacupuncture on postoperative pain and analgesic requirements in cats undergoing elective ovariohysterectomy (OHE). The hypothesis was that both LA and EA would decrease pain and the requirements for rescue analgesia, to a greater extent than pharmacological treatment alone.

\section{MATERIALS AND METHODS}

\section{Animals}

After obtaining informed consent, thirty crossbreed client-owned cats admitted for elective OHE were enrolled. The study was approved by the Institutional Animal Care Committee (protocol 2750/2015 CEUA). Only cats with normal complete blood count, serum chemistry, and American Society of Anesthesiologists physical status I (ASA I) were included in the study. The exclusion criteria were: pregnancy, lactation, aggressive behavioral, and systemic diseases. The cats arrived at the hospital at least $36 \mathrm{hr}$ prior to surgery for familiarization with the environment. All cats were evaluated preoperatively by abdominal ultrasonography for confirmation of the absence of pregnancy.

\section{Study design}

The design of this study was based on previous clinical reports on acupuncture in cats $[31,35]$. In a prospective, randomized, blinded, controlled clinical study, the cats were randomly assigned using an online software program (Research Randomizer, Computer software, http://www.randomizer.org/, Lancaster, PA, U.S.A.) to receive one of the three treatments: laser acupuncture $(\mathrm{LA}, \mathrm{n}=10)$, electroacupuncture (EA, $\mathrm{n}=10)$, and no stimulation with acupuncture (Control, $\mathrm{n}=10)$.

\section{Acupuncture application}

The acupuncture procedures were all performed by the same veterinarian who had worked with acupuncture for 13 years. For the acupuncture procedures, the cats were sedated with ketamine $(5 \mathrm{mg} / \mathrm{kg}$; Cetamin, Syntec, São Paulo, Brazil), in combination with midazolam (0.5 mg/kg; Dormonid, Cristália, Itapira, Brazil) and tramadol (2 mg/kg; Tramadon, Cristália, Brazil) administered by intramuscular (IM) route. The acupoints Stomach 36 (ST-36) and Spleen 6 (SP-6) were stimulated. The location of the acupuncture points was determined in accordance with the traditional Chinese principles, using the "cun" measurements ( 1 cun=width of the last rib) [18]. The ST-36 acupoint is located 3 cun distal to the lateral head of the fibula, in the depression lateral to the distal aspect of the cranial border of the tibial tuberosity, approximately in the middle of the cranial tibialis muscle, and SP-6 is located 3 cun proximal to the medial malleolus, at the caudal border of the tibia, close to the medial saphenous vein [43] (Fig. 1). In the EA group, the needles (Dong Bang Acupuncture, Seoul, South Korea, size $0.20 \times 20 \mathrm{~mm}$ ) were bilaterally inserted to a depth of about $10 \mathrm{~mm}$ at ST-36 and $5 \mathrm{~mm}$ at SP-6 until feeling a tissue-grab. These needles were attached to an electrical stimulator (Sikuro, Rio de Janeiro, Brazil) and were continuosly stimulated with an alternating square wave dense/disperse $0.2 \mathrm{msec}(3-300 \mathrm{~Hz})$ for 20 
min prior to surgery. The electrical stimulus started from zero and increased slowly until the animals demonstrated slight shaking of the legs and the presence of twitching. In the LA group, the same acupoints were stimulated with an infrared laser (Gallium Arsenide Laser, GaAr, Laserpulse, Ibramed, Amparo, Brazil), using the following specifications ( 904 nm wave length, power of 70 $\mathrm{mW}, 124 \mathrm{~Hz}$ and $3 \mathrm{~J} / \mathrm{cm}^{2}$ in pulsed waves, for $9 \mathrm{sec}$ in each point) [31]. The order of stimulation was: ST-36 right, ST-36 left, SP-6 right, and SP-6 left.

\section{Anesthesia and surgery}

A standardized anesthetic protocol was used. Aproximadelly 30 min after sedation, general anesthesia was induced with intravenous (IV) propofol (Propovan, Cristália, Brazil) at the dose necessary to achieve endotracheal intubation. Anesthesia was maintained with isoflurane (Isoforine, Cristália, Brazil) at an end-tidal concentration (VAMOS plus, Dräger do Brazil, Barueri, Brazil) of $1.55 \% \pm 0.23$ in $100 \%$ oxygen, using a small animal circuit without re-inhalation of gases (SAT 500, Takaoka, São Paulo, Brazil). Lactated Ringer's solution was administered at $10 \mathrm{ml} / \mathrm{kg} / \mathrm{hr}$ until recovery. OHE was performed using a standard technique through median laparotomy access in supine cats. All surgical procedures were performed by the same surgeon using a 3-cm ventral midline approach and 3-clamp technique [16]. The anesthesia time (time elapsed from the administration of propofol to discontinuation of isoflurane), surgery time (time elapsed from the first incision until placement of the last suture), time to extubation (time elapsed from termination of isoflurane until extubation), and recovery time (time elapsed from the end of anesthesia to voluntary movement into a sternal position) were recorded for each cat. Extubation was performed when the cat recovered the deglutition reflex.

\section{Postoperative assessments}

The pain and sedation scores were evaluated by an experienced single observer, blinded to the treatment allocation $2 \mathrm{hr}$ prior to surgery, and $0.5,1,2,4,6,8,12,18$, and $24 \mathrm{hr}$ after tracheal extubation. The cats were scored for signs of pain using the Interactive Visual Analogue Scale (IVAS, from $0 \mathrm{~mm}=$ no pain to $100 \mathrm{~mm}=$ maximum pain) and UNESP-Botucatu Multidimensional Composite Pain Scale (MCPS, from 0 =no pain to 30 =maximum pain) [5]. For scoring, each cat was initially evaluated for 1 $\mathrm{min}$ in its cage. Following this, the cat was stimulated to move around, for observation of reactions and behavior. Finally, the incision and surrounding area of the abdomen was palpated using 2-3 digits. Cats scoring greater than 33\% of the MCPS receiving tramadol $(2 \mathrm{mg} / \mathrm{kg})$ as rescue analgesia [31,35]. Thirty min after the first supplemental analgesia, if the MCPS score remained above 33\%, meloxicam (0.2 mg/kg IM; Movatec, Boehringer-Ingelheim, São Paulo, Brazil) was administered at a single dose. The number of cats requiring rescue analgesia and the number of additional administrations of tramadol and/or meloxicam were recorded.

A numerical rating score [11] was used for the assessment of the degree of sedation, where: $0=$ Completely awake, able to stand and walk; 1 =Stands, but staggers when attempting to walk; 2 =With encouragement is unable to stand but laying in sternal recumbency with head elevated; 3 =Able to lift head with encouragement, but resting head down, sternal recumbency; 4 $=$ Responsive to light stroking lateral recumbency; 5 =Unresponsive to light stroking lateral recumbency.

Adverse events related to the opioid administration (i.e., dysphoria, vomiting, and panting) and local adverse events in the acupuncture treated cats such as bleeding, allergic reactions, infections, and peripheral nerve injuries at the site of the needle insertion were recorded.

\section{Statistical analysis}

A sample size of at least ten cats per group was estimated to achieve $80 \%$ statistical power to detect a mean pain difference of $30 \%$ between the treated groups (LA and EA, mean MCPS expected of 5.6) and the Control group (mean MCPS expected of 8.0), and a standard deviation (SD) of 2, at an overall alpha level of 0.05. SD was estimated from a pilot study.

A Kolmogorov-Smirnov test was performed to assess the normality of the variables. Bodyweight, age, time to endotracheal extubation, and surgery and recovery times were compared using analysis of variance followed by a Tukey's test to compare differences between treatment groups. Values for pain scores were analyzed using the Kruskal-Wallis test to compare differences between treatment groups at each time point and the Friedman test was used to compare differences over time for each treatment group. The Kruskal-Wallis test was also used to compare additional analgesic requirements between the groups. The Dunn's post $h o c$ test was used when significant differences were detected. All analyses were performed using GraphPad Instat5. Differences were considered significant when $P<0.05$.

\section{RESULTS}

Thirty-six cats were screened for enrollment in the study. Six of these did not meet the inclusion criteria; two cats demonstrated aggressive behavior and four were pregnant. There were no significant differences between groups with respect to weight, age, anesthesia and surgery times, time to extubation, and recovery time $(P>0.05)$. The age of the cats ranged from 6 to 60 months $(25.6$ \pm 15 months $)$. Body weight ranged from 2.5 to $5.2 \mathrm{~kg}(2.6 \pm 0.5 \mathrm{~kg})$. Mean $\pm \mathrm{SD}$ duration of anesthesia, duration of surgery, time to extubation and recovery time were $19.6 \pm 7.3 \mathrm{~min}$ and $7.1 \pm 3 \mathrm{~min}, 12.3 \pm 3.6 \mathrm{~min}$ and $39.3 \pm 7.3 \mathrm{~min}$, respectively.

The median pain scores did not significantly differ between groups at any time point $(P>0.05)$. Compared with baseline, the IVAS and MCPS pain scores were significantly higher in the first four hours after extubation in all treatment groups (Table 1).

The number of cats requiring rescue analgesia did not differ statistically between groups. The number of doses of rescue 
Table 1. Pain and sedation scores (median and lower-upper range) measured prior to surgery (BL) and at $0.5,1,2,4,6,8,18$ and 24 hr post-extubation in cats undergoing ovariohysterectomy treated with laser acupuncture $(\mathrm{LA}, \mathrm{n}=10)$, electroacupuncture $(\mathrm{EA}, \mathrm{n}=10)$ or no acupuncture treatment (Control, $\mathrm{n}=10)$

\begin{tabular}{ccccccccccr}
\hline \multirow{2}{*}{ Scale } & \multirow{2}{*}{ Group } & \multicolumn{10}{c}{ Time (hr) } \\
\cline { 3 - 10 } & & BL & 0.5 & 1 & 2 & 4 & 8 & 12 & 18 \\
\hline IVAS & LA & $0(0-0)$ & $20(5-40)^{\text {a) }}$ & $17(10-25)^{\text {a) }}$ & $15(5-30)^{\text {a) }}$ & $10(5-30)^{\text {a) }}$ & $10(5-25)$ & $8.5(5-30)$ & $5(5-15)$ & $3.5(5-10)$ \\
$(0-100)$ & EA & $0(0-0)$ & $10(5-25)^{\text {a) }}$ & $20(5-40)^{\text {a) }}$ & $12(5-25)^{\text {a) }}$ & $10(5-30)^{\text {a) }}$ & $15(5-20)$ & $12(5-30)$ & $7.5(5-22)$ & $5(5-10)$ \\
& Control & $0(0-0)$ & $20(10-50)^{\text {a) }}$ & $30(10-0)^{\text {a) }}$ & $27(10-50)^{\text {a) }}$ & $20(5-50)^{\text {a) }}$ & $12(5-40)$ & $10(40-5)$ & $10(40-5)$ & $10(40-5)$ \\
\hline MCPS & LA & $0(0-0)$ & $5(1-8)^{\text {a) }}$ & $4.5(2-7)^{\text {a) }}$ & $3(1-7)^{\text {a) }}$ & $2(1-7)^{\text {a) }}$ & $3(1-6)$ & $2.5(1-7)$ & $1(1-3)$ & $1(1-3)$ \\
$(0-30)$ & EA & $0(0-0)$ & $5.5(2-7)^{\text {a) }}$ & $4(1-10)^{\text {a) }}$ & $3.5(2-7)^{\text {a) }}$ & $3.5(1-8)^{\text {a) }}$ & $3(1-6)$ & $3(1-5)$ & $1.5(1-4)$ & $2(1-3)$ \\
& Control & $0(0-0)$ & $6(2-14)^{\text {a) }}$ & $5.5(3-10)^{\text {a) }}$ & $5(1-9)^{\text {a) }}$ & $4(1-11)^{\text {a) }}$ & $1.5(1-5)$ & $1.5(1-6)$ & $2(1-5)$ & $2(1-5)$ \\
\hline Sedation score & LA & $0(0-0)$ & $2.5(1-4)^{\text {a) }}$ & $1.5(1-3)^{\text {a) }}$ & $1(1-2)^{\text {a) }}$ & $0.5(0-1)$ & $0(0-0)$ & $0(0-0)$ & $0(0-0)$ & $0(0-0)$ \\
$(0-5)$ & EA & $0(0-0)$ & $2(1-3)^{\text {a) }}$ & $1(1-2)^{\text {a) }}$ & $1(0-1)^{\text {a) }}$ & $0.5(0-1)$ & $0(0-0)$ & $0(0-0)$ & $0(0-0)$ & $0(0-0)$ \\
& Control & $0(0-0)$ & $2(1-4)^{\text {a) }}$ & $1(1-2)^{\text {a) }}$ & $1(1-2)^{\text {a) }}$ & $0.3(0-1)$ & $0(0-0)$ & $0(0-0)$ & $0(0-0)$ & $0(0-0)$ \\
\hline
\end{tabular}

IVAS, Interactive Visual Analogue Scale; MCPS, UNESP-Botucatu Multidimensional Composite Pain Scale. a) Significantly different from baseline $(P<0.05)$.

Table 2. Number of rescue doses administered over time in cats undergoing ovariohysterectomy treated with laser acupuncture $(L A, n=10)$, electroacupunture $(E A, n=10)$ or no acupuncture treatment (Control, $n=10)$

\begin{tabular}{|c|c|c|c|c|c|c|c|c|c|c|}
\hline \multirow{2}{*}{ Group } & \multicolumn{8}{|c|}{ Postoperative time (hr) } & \multirow{2}{*}{$\begin{array}{l}\text { Total number of } \\
\text { rescue doses }\end{array}$} & \multirow{2}{*}{$\begin{array}{l}\text { Total number of } \\
\text { rescued cats }\end{array}$} \\
\hline & 0.5 & 1 & 2 & 4 & 8 & 12 & 18 & 24 & & \\
\hline LA & 0 & 1 & 0 & 0 & 0 & 0 & 0 & 0 & $1^{\text {a) }}$ & $1 / 10$ \\
\hline EA & 0 & 0 & 0 & 1 & 0 & 0 & 0 & 0 & $1^{\text {a) }}$ & $1 / 10$ \\
\hline Control & 1 & 3 & 2 & 2 & 0 & 0 & 0 & 0 & 8 & $5 / 10$ \\
\hline
\end{tabular}

a) Significantly different from Control group (Kruskal-Wallis, $P=0.033$ ).

analgesia administered was significantly higher in the Control group than in the LA and EA groups $(P=0.033)$, but not between the LA and EA groups $(P>0.05)$. One of 10 cats in the LA and EA groups, received one dose of tramadol as rescue analgesia in the 24-hr period following surgery. Five of 10 cats in the Control group required rescue analgesia in the same period. Two cats required rescue analgesia on one occasion (one dose of tramadol for each), and three cats required rescue analgesia on two occasions (two cats received one dose of tramadol and one dose of meloxicam, and one cat received two doses of tramadol) (Table 2).

No statistically significant differences were observed in sedation scores between treatment groups $(P>0.05)$ (Table 1$)$. No adverse events were observed during the study.

\section{DISCUSSION}

These data suggest that preoperative EA and LA, as adjuvant therapies, significantly decreased $(P=0.033)$ the requirements for rescue analgesia in the 24-hr period following OHE in cats, confirming, in part, the hypothesis of this study. This result is supported by clinical reports, where perioperative acupuncture reduced the need for supplemental analgesics after mastectomy [17] and ovariohysterectomy $[7,31]$ in small animals.

In agreement with other reported studies $[6,35], 50 \%$ of the cats treated only with tramadol $(2 \mathrm{mg} / \mathrm{kg})$ preoperatively required rescue analgesia after OHE. In contrast, only $10 \%(1 / 10)$ of the cats receiving LA and EA, respectively, needed postoperative supplemental analgesia. In addition, for the acupuncture treated cats only one additional dose of tramadol was required, while for the control treated cats, meloxicam was required on two occasions, and a second dose of tramadol was required in one cat. These findings suggest that both acupuncture methods used in this report were effective in providing postoperative analgesia.

Based on western theories, the sensory stimuli triggered by the acupuncture needles are conducted by the A- $\delta$ fibers into the spinal cord, stimulating the release of different neurotransmitters able to suppress pain presynaptically and postsynaptically due to the decrease in transmission of the stimuli through the spinothalamic tract $[23,30]$. It has been reported that both opioid and serotoninergic mechanisms are involved in the antinociceptive effects elicited by the EA stimulation [9]. Similarly, recent findings have also demonstrated involvement of the opioidergic and serotonergic systems in the antinociceptive effect mediated by laser acupuncture [13]. As tramadol is known to produce analgesia by a dual mechanism of effect, including opioid action sites and the central monoaminergic inhibitory system [4], it is suggested that the preoperative provision of this drug may have interfered in the analgesic effect elicited by both acupuncture methods applied in the current study.

Although opioidergic and serotoninergic mechanisms play an important role in pain modulation, other neurotransmitters such as catecholamines, glutamate and $\alpha$-aminobutiric acid (GABA) are also involved in the acupuncture analgesic effect [30]. Based on the different antinociceptive mechanisms of acupuncture, the pretreatment with ketamine and midazolam in the current study could also have interfered in the analgesic response. Low dose infusions of ketamine have been reported to provide postoperative 
analgesic effects in both human and veterinary medicine $[19,20,40]$. The antinociceptive effects of ketamine are mediated by different mechanisms, including N-methyl-d-aspartate (NMDA) receptors, nicotinic/muscarinic cholinergic receptors, and adrenergic and opioid receptors [12]. In addition, midazolam is a benzodiazepine that potentiates the GABAergic activity, which could interfere in the acupuncture response, since the GABAergic system is also involved in the analgesic mechanisms of acupuncture [34]. To date, few studies have investigated the interference of ketamine and benzodiazepines on acupuncture-induced analgesia. Results of previous laboratory animal studies indicated that ketamine may induce an antagonistic effect on acupuncture analgesia $[44,45]$. In rats, the analgesic effects of EA were attenuated after intraperitoneal administration of $4 \mathrm{and} 20 \mathrm{mg} / \mathrm{kg}$ of ketamine [45]. Similarly, in experimental studies, pretreatment with diazepam reduced the antinociceptive effect mediated by EA [10]. Currently there are no published investigations on the analgesic efficacy mediated by acupuncture in cats pretreated with ketamine and midazolam. In view of these results, it is likely that sedation of the cats may have exerted some interference on the EA and LA analgesic responses, but this study cannot confirm this effect.

The analgesic effects elicited by acupuncture may be influenced by the characteristics of the applied stimuli. When EA is applied, analgesia is achieved through integration of the wave, pulse width, frequency, and intensity of stimulation on the acupoints $[41,43]$. Among these factors, frequency is a key factor affecting the analgesic effect of EA. Both low-frequency and high-frequency stimulation have been found to induce analgesia, however different types of neurotransmitters are released [41, 42]. Low-frequency EA induces the release of endorphin and enkephalin, resulting in an analgesic effect of slower onset and longer duration that can be reversed by naloxone [42]. In contrast, high-frequency induced-analgesia has a more rapid onset with a shorter duration and cannot be blocked by naloxone, suggesting the participation of non-opioid mechanisms such as serotonin and norepinephrine [33]. The dense-disperse mode of electrical stimulation used in the present study, with a frequency ranging from 3 to $300 \mathrm{~Hz}$, probably produced the release of a combination of endogenous opioids. Similarly, when laser is applied, the radiation characteristics also interfere with the analgesic response [29]. It has been suggested that the application of an infrared laser with a wavelength of between 650 and 1,000 nm has a penetration depth of 2 to $3 \mathrm{~mm}$ [37], which can trigger effective stimulation of the acupoint [29]. In addition, the stimulation of acupuncture points with laser using radiation intensities ranging from 3 to $10 \mathrm{~J} / \mathrm{cm}^{2}$ has been associated with effective analgesic response [31, 38]. For these reasons, it can be suggested that the radiation characteristics (wave length $904 \mathrm{~nm}$; intensity of $3 \mathrm{~J} / \mathrm{cm}^{2}$ ) applied in the current study may have contributed to the analgesic effect.

Despite the lower incidence of rescue medication in acupuncture treated cats, neither the IVAS nor MCPS was sensitive enough to detect differences in pain levels between groups. Other studies also failed to demonstrate significant differences in pain scores between groups when the IVAS [2,3] or the MCPS scale was used in cats [2, 31]. The IVAS is a subjective evaluation method that includes observation and interaction with the cat by a trained observer, however, this scale has not been properly validated in cats and may not be sensitive enough under all conditions [3]. The MCPS is a validated pain scale for assessing pain in cats [5]. This method involves assessment of three subscales: pain expression, psychomotor changes, and physiologic variables. Given the subjectivity of these scoring systems, the observer training is pivotal to the identification of pain. Despite the assessor training, it is still likely that the findings of this study may be attributed to the lack of the assessor's experience with subjective scales. In addition, all the surgery procedures were performed by one experienced surgeon, resulting in minimal tissue trauma, which may have resulted in low postoperative pain scores. The majority of the cats appeared comfortable in the postoperative period. The median postoperative pain scores were below $30 \mathrm{~mm}(0-100 \mathrm{~mm})$ and 7 (0-30 points), based on the IVAS and MCPS, respectively. Thus, the low pain scores could make it difficult to establish differences between the groups.

Although tramadol is not classified as a pure opioid, it can produce adverse behavior responses in cats, including excitation, euphoria, and panting [4]. None of these adverse effects were observed in the current study. In addition, no local adverse effects related to acupuncture were identified in the LA and EA treatments, suggesting that both methods of acupuncture are safe alternatives to provide analgesia in cats. These findings are supported by previous studies that reported the safety of acupuncture therapy in dogs $[7,17]$ and cats $[31,35]$.

The design of the current study has some limitations. The lack of statistically significant differences in the pain scores between groups could be attributed to the small sample size. In addition, the inclusion of a control negative group may have been useful in detecting a subtle treatment effect; however, it is well recognized that pain is evident in cats after elective OHE and previous studies have shown that postoperative pain was detected in $100 \%$ of cats undergoing OHE without preventive analgesic treatment $[5,6]$. For ethical reasons, a negative control group was not included. Indeed, the study design did not include a placebo acupuncture group. It has been reported that placebo acupuncture (needles inserted into non-acupuncture points) may also produce an analgesic response, although more profound effects are achieved by real point stimulation [36]. The stimulation of sham points reduced the pain threshold in dogs [8], rats [33], and rabbits [39]; however, the stimulation of real points provides a more intense response. Due to the low analgesic efficacy reported with false point stimulation, the decision was taken not to include a placebo acupuncture group. Another limitation of this study was the mode of the alternating stimulation of the acupuncture points with low $(3 \mathrm{~Hz})$ and high $(300 \mathrm{~Hz})$ frequency, leading to release of various neurotransmitters, which could result in competition with some drugs, such as tramadol and ketamine, for the opioid receptors, interfering in the analgesic effect. To date, few studies have investigated the combination of acupuncture and pharmacological protocols for pain relief. Additional studies are needed to clarify the possible interference of these drugs on the acupuncture-induced analgesia under clinical conditions.

In conclusion, both methods of acupuncture in combination with a single dose of tramadol reduced the postoperative analgesic requirements following OHE in cats. Additionally, from a clinical point of view, in comparison with EA, LA has the advantage of being a painless, noninvasive, and easier method to apply. Larger and sham-controlled studies are needed to support these results. 
ACKNOWLEDGMENT. Supported by the “Fundação de Amparo à Pesquisa de São Paulo“" (grant number 2013/20931-9).

\section{REFERENCES}

1. Belletti, S., Uggeri, J., Mergoni, G., Vescovi, P., Merigo, E., Fornaini, C., Nammour, S., Manfredi, M. and Gatti, R. 2015. Effects of 915 nm GaAs diode laser on mitochondria of human dermal fibroblasts: analysis with confocal microscopy. Lasers Med. Sci. 30: 375-381. [Medline] [CrossRef]

2. Benito, J., Monteiro, B., Lavoie, A. M., Beauchamp, G., Lascelles, B. D. X. and Steagall, P. V. 2016. Analgesic efficacy of intraperitoneal administration of bupivacaine in cats. J. Feline Med. Surg. 18: 906-912. [Medline] [CrossRef]

3. Benito-de-la-Víbora, J., Lascelles, B. D., García-Fernández, P., Freire, M. and de Segura, I. A. 2008. Efficacy of tolfenamic acid and meloxicam in the control of postoperative pain following ovariohysterectomy in the cat. Vet. Anaesth. Analg. 35: 501-510. [Medline] [CrossRef]

4. Bortolami, E. and Love, E. J. 2015. Practical use of opioids in cats: a state-of-the-art, evidence-based review. J. Feline Med. Surg. 17: $283-311$. [Medline] [CrossRef]

5. Brondani, J. T., Mama, K. R., Luna, S. P. L., Wright, B. D., Niyom, S., Ambrosio, J., Vogel, P. R. and Padovani, C. R. 2013. Validation of the English version of the UNESP-Botucatu multidimensional composite pain scale for assessing postoperative pain in cats. BMC Vet. Res. 9: 143. [Medline] [CrossRef]

6. Brondani, J. T., Loureiro Luna, S. P., Beier, S. L., Minto, B. W. and Padovani, C. R. 2009. Analgesic efficacy of perioperative use of vedaprofen, tramadol or their combination in cats undergoing ovariohysterectomy. J. Feline Med. Surg. 11: 420-429. [Medline] [CrossRef]

7. Cassu, R. N., Silva, D. A., Genari Filho, T. and Stevanin, H. 2012. Electroanalgesia for the postoperative control pain in dogs. Acta Cir. Bras. 27: 43-48. [Medline] [CrossRef]

8. Cassu, R. N., Luna, S. P., Clark, R. M. and Kronka, S. N. 2008. Electroacupuncture analgesia in dogs: is there a difference between uni- and bi-lateral stimulation? Vet. Anaesth. Analg. 35: 52-61. [Medline] [CrossRef]

9. Ceccherelli, F., Gagliardi, G., Visentin, R., Sandona, F., Casale, R. and Giron, G. 1999. The effects of parachlorophenylalanine and naloxone on acupuncture and electroacupuncture modulation of capsaicin-induced neurogenic edema in the rat hind paw. A controlled blind study. Clin. Exp. Rheumatol. 17: 655-662. [Medline]

10. Chakrabarti, S. and Poddar, M. K. 1989. Effect of diazepam on electroacupuncture-induced changes in regional gamma-aminobutyric acid of the rat central nervous system. Neurosci. Res. 7: 24-32. [Medline] [CrossRef]

11. Dobbins, S., Brown, N. O. and Shofer, F. S. 2002. Comparison of the effects of buprenorphine, oxymorphone hydrochloride, and ketoprofen for postoperative analgesia after onychectomy or onychectomy and sterilization in cats. J. Am. Anim. Hosp. Assoc. 38: 507-514. [Medline] [CrossRef]

12. Elia, N. and Tramèr, M. R. 2005. Ketamine and postoperative pain - a quantitative systematic review of randomised trials. Pain 113: 61-70. [Medline] [CrossRef]

13. Erthal, V., da Silva, M. D., Cidral-Filho, F. J., Santos, A. R. and Nohama, P. 2013. ST36 laser acupuncture reduces pain-related behavior in rats: involvement of the opioidergic and serotonergic systems. Lasers Med. Sci. 28: 1345-1351. [Medline] [CrossRef]

14. Ferraresi, C., Kaippert, B., Avci, P., Huang, Y. Y., de Sousa, M. V., Bagnato, V. S., Parizotto, N. A. and Hamblin, M. R. 2015. Low-level laser (light) therapy increases mitochondrial membrane potential and ATP synthesis in $\mathrm{C} 2 \mathrm{C} 12$ myotubes with a peak response at 3-6 h. Photochem. Photobiol. 91: 411-416. [Medline] [CrossRef]

15. Fletcher, D. and Martinez, V. 2014. Opioid-induced hyperalgesia in patients after surgery: a systematic review and a meta-analysis. Br. J. Anaesth. 112: 991-1004. [Medline] [CrossRef]

16. Fossum, T. W. 2018. Small animal surgery, 5th ed., Elsevier Mosby, St. Louis, Missouri.

17. Gakiya, H. H., Silva, D. A., Gomes, J., Stevanin, H. and Cassu, R. N. 2011. Electroacupuncture versus morphine for the postoperative control pain in dogs. Acta Cir. Bras. 26: 346-351. [Medline] [CrossRef]

18. Gaynor, J. S. 2000. Acupuncture for management of pain. Vet. Clin. North Am. Small Anim. Pract. 30: 875-884, viii. [Medline] [CrossRef]

19. Gutierrez-Blanco, E., Victoria-Mora, J. M., Ibancovichi-Camarillo, J. A., Sauri-Arceo, C. H., Bolio-González, M. E., Acevedo-Arcique, C. M., Marin-Cano, G. and Steagall, P. V. 2015. Postoperative analgesic effects of either a constant rate infusion of fentanyl, lidocaine, ketamine, dexmedetomidine, or the combination lidocaine-ketamine-dexmedetomidine after ovariohysterectomy in dogs. Vet. Anaesth. Analg. 42: 309-318. [Medline] [CrossRef]

20. Hirota, K. and Lambert, D. G. 2011. Ketamine: new uses for an old drug? Br. J. Anaesth. 107: 123-126. [Medline] [CrossRef]

21. Hu, W. L., Chang, C. H., Hung, Y. C., Tseng, Y. J., Hung, I. L. and Hsu, S. F. 2014. Laser acupuncture therapy in patients with treatment-resistant temporomandibular disorders. PLoS One 9: e110528. [Medline] [CrossRef]

22. Hutchinson, M. R., Bland, S. T., Johnson, K. W., Rice, K. C., Maier, S. F. and Watkins, L. R. 2007. Opioid-induced glial activation: mechanisms of activation and implications for opioid analgesia, dependence, and reward. Sci. World J. 7: 98-111. [Medline] [CrossRef]

23. Kawakita, K., Shinbara, H., Imai, K., Fukuda, F., Yano, T. and Kuriyama, K. 2006. How do acupuncture and moxibustion act? - Focusing on the progress in Japanese acupuncture research -. J. Pharmacol. Sci. 100: 443-459. [Medline] [CrossRef]

24. Kotani, N., Hashimoto, H., Sato, Y., Sessler, D. I., Yoshioka, H., Kitayama, M., Yasuda, T. and Matsuki, A. 2001. Preoperative intradermal acupuncture reduces postoperative pain, nausea and vomiting, analgesic requirement, and sympathoadrenal responses. Anesthesiology 95: 349-356. [Medline] [CrossRef]

25. Lamont, L. A. 2008. Multimodal pain management in veterinary medicine: the physiologic basis of pharmacologic therapies. Vet. Clin. North Am. Small Anim. Pract. 38: 1173-1186. [Medline] [CrossRef]

26. Langevin, H. M., Keely, P., Mao, J., Hodge, L. M., Schleip, R., Deng, G., Hinz, B., Swartz, M. A., de Valois, B. A., Zick, S. and Findley, T. 2016. Connecting (T)issues: How Research in Fascia Biology Can Impact Integrative Oncology. Cancer Res. 76: 6159-6162. [Medline] [CrossRef]

27. Langevin, H. M. 2014. Acupuncture, connective tissue, and peripheral sensory modulation. Crit. Rev. Eukaryot. Gene Expr. 24: 249-253. [Medline] [CrossRef]

28. Lin, J. G., Lo, M. W., Wen, Y. R., Hsieh, C. L., Tsai, S. K. and Sun, W. Z. 2002. The effect of high and low frequency electroacupuncture in pain after lower abdominal surgery. Pain 99: 509-514. [Medline] [CrossRef]

29. Litscher, G. 2009. Ten years evidence-based high-tech acupuncture-a short review of peripherally measured effects. Evid. Based Complement. Alternat. Med. 6: 153-158. [Medline] [CrossRef]

30. Ma, S. X. 2004. Neurobiology of acupuncture: toward CAM. Evid. Based Complement. Alternat. Med. 1: 41-47. [Medline] [CrossRef]

31. Marques, V. I., Cassu, R. N., Nascimento, F. F., Tavares, R. C., Crociolli, G. C., Guilhen, R. C. and Nicácio, G. M. 2015. Laser acupuncture for postoperative pain management in cats. Evid. Based Complement. Alternat. Med. 2015: 653270. [Medline] [CrossRef] 
32. Mathews, K., Kronen, P. W., Lascelles, D., Nolan, A., Robertson, S., Steagall, P. V., Wright, B. and Yamashita, K. 2014. Guidelines for recognition, assessment and treatment of pain: WSAVA Global Pain Council members and co-authors of this document. J. Small Anim. Pract. 55: E10-E68. [Medline] [CrossRef]

33. Oliveira, R. and Prado, W. A. 2000. Anti-hyperalgesic effect of electroacupuncture in a model of post-incisional pain in rats. Braz. J. Med. Biol. Res. 33: 957-960. [Medline] [CrossRef]

34. Qiao, L. N., Liu, J. L., Tan, L. H., Yang, H. L., Zhai, X. and Yang, Y. S. 2017. Effect of electroacupuncture on thermal pain threshold and expression of calcitonin-gene related peptide, substance $\mathrm{P}$ and $\gamma$-aminobutyric acid in the cervical dorsal root ganglion of rats with incisional neck pain. Acupunct. Med. 35: 276-283. [Medline] [CrossRef]

35. Ribeiro, M. R., de Carvalho, C. B., Pereira, R. H. Z., Nicácio, G. M., Brinholi, R. B. and Cassu, R. N. 2017. Yamamoto new scalp acupuncture for postoperative pain management in cats undergoing ovariohysterectomy. Vet. Anaesth. Analg. 44: 1236-1244. [Medline] [CrossRef]

36. Sim, C. K., Xu, P. C., Pua, H. L., Zhang, G. and Lee, T. L. 2002. Effects of electroacupuncture on intraoperative and postoperative analgesic requirement. Acupunct. Med. 20: 56-65. [Medline] [CrossRef]

37. Stolik, S., Delgado, J. A., Pérez, A. and Anasagasti, L. 2000. Measurement of the penetration depths of red and near infrared light in human "ex vivo" tissues. J. Photochem. Photobiol. B 57: 90-93. [Medline] [CrossRef]

38. Taffarel, M. O., Cardoso, G. S., Luna, S. P. L., Derussi, A. A. P., Volpato, R., Guaitolini, C. R. F. and Ackerman, C. 2013. Preemptive analgesia with laserpuncture in dogs undergoing ovariohysterectomy. Vet. Anaesth. Analg. 40: 4.

39. Takeshige, C. 1985. Differentiation between acupuncture and non-acupuncture points by association with analgesia inhibitory system. Acupunct. Electrother. Res. 10: 195-202. [Medline] [CrossRef]

40. Vadivelu, N., Schermer, E., Kodumudi, V., Belani, K., Urman, R. D. and Kaye, A. D. 2016. Role of ketamine for analgesia in adults and children. $J$. Anaesthesiol. Clin. Pharmacol. 32: 298-306. [Medline] [CrossRef]

41. White, P. F., Li, S. and Chiu, J. W. 2001. Electroanalgesia: its role in acute and chronic pain management. Anesth. Analg. 92: 505-513. [Medline] [CrossRef]

42. Xiang, X. H., Chen, Y. M., Zhang, J. M., Tian, J. H., Han, J. S. and Cui, C. L. 2014. Low- and high-frequency transcutaneous electrical acupoint stimulation induces different effects on cerebral $\mu$-opioid receptor availability in rhesus monkeys. J. Neurosci. Res. 92: 555-563. [Medline] [CrossRef]

43. Xie, H. and Preast, V. 2007. Xie's Veterinary Acupuncture. Blackwell Publishing Professional, Ames, Iowa.

44. Xu, S. F., Cao, X. D., Mo, W. Y., Xu, Z. B. and Pan, Y. Y. 1989. Effect of combination of drugs with acupuncture on analgesic efficacy. Acupunct. Electrother. Res. 14: 103-113. [Medline] [CrossRef]

45. Xu, W., Yan, Y. S. and Chen, Z. Q. 1989. [Effect of ketamine on acupuncture analgesia]. Zhen Ci Yan Jiu 14: $428-430$ (in Chinese). [Medline] 